\title{
Does offspring sex ratio differ between urban and forest populations of great tits (Parus major)?
}

\author{
Nóra Ágh ${ }^{1} \cdot$ Ivett Pipoly $^{1} \cdot$ Krisztián Szabó $^{2} \cdot$ Ernő Vincze $^{1} \cdot$ Veronika Bókony $^{3} \cdot$ Gábor Seress $^{1} \cdot$ András Liker $^{1}$
}

Received: 25 September 2019 / Accepted: 1 June 2020 / Published online: 25 June 2020

(c) The Author(s) 2020

\begin{abstract}
Since male and female offspring may have different costs and benefits, parents may use sex ratio adjustment to increase their own fitness under different environmental conditions. Urban habitats provide poorer conditions for nestling development in many birds. Therefore, we investigated whether great tits (Parus major) produce different brood sex ratios in urban and natural habitats. We determined the sex of nestlings of 126 broods in two urban and two forest sites between 2012 and 2014 by molecular sexing. We found that brood sex ratio did not differ significantly between urban and forest habitats either at egg-laying or near fledging. Male offspring were larger than females in both habitats. This latter result suggests that male offspring may be more costly to raise than females, yet our findings suggest that urban great tits do not produce more daughters despite the unfavourable breeding conditions. This raises the possibility that other aspects of urban life, such as better post-fledging survival, might favour males and thereby compensate for the extra energetic costs of producing male offspring.
\end{abstract}

Keywords Brood sex ratio $\cdot$ Urbanization $\cdot$ Sexual size dimorphism $\cdot$ Sex-dependent mortality $\cdot$ Tarsus length

\section{Introduction}

In birds, brood sex ratio often differs from parity, and the direction and extent of this difference seem to be not random. Females in many bird species appear to optimize brood sex ratio according to the cost and fitness outcome of producing male and female offspring, which may vary among environments as well as with the quality of the parents [65]. For example, one sex may have higher growth rate than the other, resulting in sexual size dimorphism (one sex having

Electronic supplementary material The online version of this article (https://doi.org/10.1007/s42977-020-00024-6) contains supplementary material, which is available to authorized users.

Nóra Ágh

agh.nora@mk.uni-pannon.hu

1 MTA-PE Evolutionary Ecology Research Group, Department of Limnology, University of Pannonia, Veszprém, Hungary

2 Conservation Genetic Research Group, Institute of Biology, University of Veterinary Medicine Budapest, Budapest, Hungary

3 Lendület Evolutionary Ecology Research Group, Plant Protection Institute, Centre for Agricultural Research, Budapest, Hungary larger body size than the other). This may be one of the main causes of the unequal costs of male and female offspring to parents (e.g. [42, 55, 51]), as a faster-growing or larger offspring needs larger amounts of food, thus requiring higher parental effort (e.g. [2, 34]). Sexual size dimorphism is widespread in birds, both in eggs (e.g. [22, 23]) and nestlings (e.g. larger females: [3, 44]; larger males: [31, $28,5,66])$. Sex differences in offspring survival rate also affect the relative values of males and females. For example, different sensitivity of males and females to environmental stressors like parasites may induce higher nestling mortality in one sex compared to the other. The larger sex is more likely to be the more sensitive one, because there may be a trade-off between growth and immunocompetence, and the larger sex may allocate more resources in the former at the expense of the latter (e.g. [66] but see [12]). Furthermore, after fledging, the sexes can also greatly differ in their dispersal distance (see examples in Végvári et al. [67]), mortality and lifespan (e.g. [41, 8]). These components of male and female life history can be highly dependent on environmental factors (for a theoretical model see Julliard [32]). Accordingly, the optimal brood sex ratio can differ between different environments. For example, mothers may produce more offspring of the less vulnerable sex in years or habitats with poor dietary conditions, to optimize their parental 
investment and increase the number of surviving offspring [37, 49]. For instance, Komdeur [35] found in the Seychelles warbler (Acrocephalus sechellensis) that producing more females (which remain longer in their natal territories than males) on low-quality territories reduces the parents' future breeding success, whereas on high-quality territories female offspring stay as helpers, increasing their parents' breeding success. Therefore, parents with high-quality territories are more likely to produce daughters, whereas in low-quality territories they are more likely to produce more sons.

Urban and non-urban habitats often differ in quality and structure, leading to cardinal changes in life history and breeding phenology of birds in anthropogenic environments $[27,19]$. For instance, urban birds often start breeding earlier and have smaller clutches than those in natural habitats (reviewed in Sepp et al. [56], examples for great tit: Bailly et al. [6], Charmantier et al. [20] and Seress et al. [59]). In cities, body condition of fledglings is also often poorer and their mortality rate is higher, which may be compensated for by better adult survival (reviewed in Chamberlain et al. [19], Seress and Liker [57] and [11]). Thus, urbanization may change the relative benefits of male and female offspring, which may favour facultative adjustment of offspring sex ratios by parents. In urban environments, reduced availability of natural food sources like arthropods during brood rearing (see e.g. Seress et al. [59]) may have a stronger negative effect on the faster-growing and larger offspring, making the smaller sex more profitable for parents (for similar effects in non-urbanization context, see Rosivall et al. [54]). Furthermore, competition for the scarce arthropod food sources may continue after fledging and might be stronger in urban habitats with unfavourable local conditions than in forests, which predicts that parental investment should be biased towards the more-dispersing sex [32]. Thus, studying offspring sex ratios may contribute to a better understanding of how animals adapt to urban environments. However, our knowledge regarding sex ratio adjustment in urban environments is still very limited (e.g. Dhondt [24], Rejt et al. [52] and Bonderud et al. [13]).

Beside environmental conditions, parental quality is another factor that can influence the future reproductive success of male and female offspring, and thus may also affect the brood sex ratio. On the one hand, the "mate attractiveness hypothesis" $[17,18]$ states that females mating with males with attractive heritable traits should produce more sons than those who mate with unattractive males because the formers' sons will be more desirable for females and thus can achieve higher breeding success (e.g. West et al. [69], Komdeur and Pen [36] and Yamaguchi et al. [70]; reviewed in Booksmythe et al. [14]). Larger body size (e.g. as indicated by tarsus length in great tits: Yamaguchi et al. [70]) may be one of these attractive heritable male traits. On the other hand, parents of larger body size or in better condition may provide higher-quality parental care, which can also influence parents' decision on optimal sex allocation. This latter idea predicts that higher-quality parents who can provide adequate care under unfavourable conditions (e.g. can provide more and better prey items to the nestlings) will produce more offspring of the more vulnerable sex than lower-quality parents. This, again, predicts an overproduction of the less sensitive sex in urban broods, because body size and condition are in some cases reduced in urban adults, although in other cases the opposite or no difference was observed (reviewed in: Seress and Liker [57] and Sepp et al. [56]).

In this study, we investigated the effects of urbanization on brood sex ratio in the great tit, a passerine bird that occupies a wide range of habitats [16]. Great tits are successful urban colonizers, but in cities they often show reduced clutch size, lower nestling mass, and fledging success compared to forest areas $[6,19,29,59]$, likely because of the lower availability of natural prey as nestling food in urban habitats [59, 60]. In this species, an earlier study found signs of facultative sex ratio adjustment, as primary sex ratios varied with date, clutch size and hatching asynchrony [40]. Also, great tit brood sex ratios were found to vary with tarsus length of the father [38] and body condition of the mother [63]. Other studies suggest that different sensitivity of the sexes to habitat quality can also affect the brood sex ratio in this species. For example, Bouvier et al. [15] found that the sex ratio of fledglings was more biased towards females in orchards with high levels of pesticide treatments (hence reduced food availability) compared to moderately treated or organic gardens. Similarly, breeding territory quality may also predict brood sex ratio in woodland great tits: Stauss et al. [63] found that in deciduous forests, where caterpillars (the preferred nestling food) were abundant, broods were more male-biased than in coniferous forests that had reduced caterpillar availability. However, to our knowledge, only a single earlier study investigated habitat-related effects on offspring sex ratios in great tits in an urbanization context [24]. Furthermore, these earlier studies investigated only the fledgling sex ratio (which can change due to parental adjustment and/or sex-dependent mortality) and not the primary sex ratio (i.e. which depends only on parental adjustment).

In great tits, male offspring are larger and may be more sensitive to poor environmental conditions [66], whereas females disperse further and thereby may escape more successfully from unfavourable local conditions [4]. So, based on the aforementioned results, we predicted that great tits would produce more female-biased broods in the foodlimited urban habitats than in natural forests where optimal nestling food is abundant. We tested this prediction using breeding data from 3 years of monitoring of four populations, two in cities and two in nearby deciduous woodlands. We investigated both the primary sex ratio (i.e. sex ratio at 
egg-laying) and fledgling sex ratio, and we took into account other factors that may influence brood sex ratios, including laying date and, as a proxy for parental quality, parental body size (e.g. Kölliker et al. [38], Rosivall et al. [55] and Bell et al. [10]). Using data on fledgling body size and nestling survival, we also evaluated whether male offspring are larger and more sensitive (in terms of nestling mortality) than females in the studied populations.

\section{Materials and methods}

\section{Field methods}

We studied great tit populations in two forests and two urban sites in Hungary. Forest sites were located in deciduous woodlands near Szentgál (47 06' 39.75" N, $17^{\circ} 41^{\prime} 17.94^{\prime \prime}$ E) and in Vilma-puszta $\left(47^{\circ} 05^{\prime} 06.7^{\prime \prime} \mathrm{N}, 17^{\circ} 51^{\prime} 51.4^{\prime \prime} \mathrm{E}\right)$, whereas the two urban sites were located in the cities of Veszprém (47 $\left.05^{\prime} 17.29^{\prime \prime} \mathrm{N}, 17^{\circ} 54^{\prime} 29.66^{\prime \prime} \mathrm{E}\right)$ and Balatonfüred $\left(46^{\circ} 57^{\prime} 30.82^{\prime \prime} \mathrm{N}, 17^{\circ} 53^{\prime} 34.47^{\prime \prime} \mathrm{E}\right)$. We collected data at all study sites from 2012 to 2014, except for Balatonfüred, where data collection started in 2013. Nest boxes in the urban habitats were placed mostly in public parks and university campuses; all of these plots were strongly influenced by anthropogenic disturbance (e.g. presence of vehicle traffic and human activity; see Seress et al. [59] for more details on the study sites). We monitored the nest boxes at least twice a week from March to early July to record laying date of the first egg, clutch size, hatching dates, and the number of nestlings (detailed in Seress et al. [58]). We ringed all nestlings just before fledging (at 14-16 days of age, day 1 being the hatching day of the first-hatching nestlings) and measured the length of their left tarsus to the nearest $0.1 \mathrm{~mm}$ and their right wing (the flattened maximum wing chord, from the carpus to the tip of the longest primary; [64]) to the nearest $\mathrm{mm}$, and recorded their body mass (to the nearest $0.1 \mathrm{~g}$ using Pesola spring balance). We also took a small drop of blood (ca. $25 \mu \mathrm{l}$ ) from the brachial vein. In 2013-2014, we collected unhatched eggs (that did not hatch for at least 5 days after the first chick of the same brood hatched) and a small tissue sample (e.g. feather, toes) from chicks found dead in the nest during nest box checking throughout the brood rearing period. We stored all samples either in Queen's lysis solution [61] or in 96\% ethanol at $4{ }^{\circ} \mathrm{C}$ until further analysis. We captured adult birds on their nests during brood rearing and ringed each bird with a unique combination of a numbered metal ring and three plastic colour rings for individual identification. To increase the number of individually identified birds in our populations, we also colour-ringed adult great tits outside of the breeding season (from late September to early February) at the four study sites using mist-nets. Thus, parents of the broods included in our analyses were identified either by capturing them on their nests during brood rearing or by observing their colour ring combinations from video recordings filmed with concealed nest cameras (see Seress et al. [58] for details). In these video samples, we considered a colour-ringed individual to be a parent bird if it was recorded to enter the nest box with food at least once. For measuring and sampling adult birds, we followed the same protocol described above for fledglings.

\section{Laboratory methods}

We extracted DNA by using silica membrane isolation kits (GeneJET, Genomic DNA Purification Kit) following the manufacturers' protocol (Thermo Scientific ${ }^{\mathrm{TM}}$ ). Molecular sexing was performed using the primer pairs P2-P8 with the protocol of Griffiths et al. [26]. We investigated all unhatched eggs for the presence of an embryo before DNA isolation. If we noticed no sign of embryo development (not even a visible germinal disc), we classified them as infertile eggs. Out of 44 unhatched eggs, we found 30 infertile eggs. We preserved the embryos from the 14 fertile eggs in $96 \%$ ethanol. We then extracted a small sample of tissue from the embryos and the further DNA isolation steps were similar to the methods we used for blood and other tissue samples. All embryos were successfully sexed. We were also able to successfully extract DNA from all of the tissue samples of the dead nestlings.

We analysed 126 broods (14 from 2012, 52 from 2013, and 60 from 2014, details in Supplementary Table S1) where we had blood or other tissue samples from nearly all offspring (i.e. missing tissue sample from no more than 3 dead offspring per brood). We could take DNA samples from offspring in all the laid eggs and thereby calculate the primary sex ratio for 79 broods ( 6 from 2012, 34 from 2013, and 39 from 2014). The 6 broods from 2012 that we could include in the primary sex ratio analyses were nests where all laid eggs had become successful fledglings (i.e. there were no unhatched eggs or dead nestlings); in 2013-2014 we were able to study primary sex ratios by sampling dead offspring. In the remaining 47 broods ( 8 from 2012, 18 from 2013, and 21 from 2014) we could estimate only the fledgling sex ratio (i.e. at the age of ringing, at 14-16 days). We aimed to sample both the first and second annual broods at each study site. We categorized each brood as the first annual breeding attempt of a pair if it was initiated before the date of the first egg laid in the earliest identified second clutch in that year at that study site (i.e. clutch by a colour-ringed female that had already successfully fledged at least one young in that year). Broods initiated after this date were categorized as second annual breeding attempts. Our sample size is inherently unbalanced (Table S1), because the number of available broods differed between sites and years, and changed 
over the season (i.e. there were fewer second broods than first broods). For the 126 broods, we were able to identify 240 parents, out of which 111 fathers and 118 mothers were measured as adults (the remaining 11 birds were only measured and ringed as nestlings in the previous year). In total, we had 105 broods were both parents were identified and measured.

\section{Statistical analyses}

We calculated primary and fledgling sex ratios as the number of males divided by the total number of offspring or nestlings. Primary sex ratio means the sex ratio of all offspring (embryos, dead chicks, and chicks that reached the fledging age) in completely sexed broods, whereas fledgling sex ratio means the sex ratio of nestlings that reached the fledging age (without embryos or dead chicks). We analysed the data from the first and second annual broods together and used the laying date as a covariate in all analyses. We calculated laying date in two alternative ways and used these two variables in two alternative sets of models. First, we used laying date as the absolute number of days since 1 January until the laying of the first egg in the brood (days $1=1$ January). This variable reflects brood value, as offspring fledging later in the season have less time for post-fledging growth before winter. Second, to test the specific effect of timing within the breeding season in each year at each study site, we used mean-centred laying date, subtracting the mean of the respective site and year from each brood's laying date. This variable captures a different aspect of the date effect, as the start of the breeding season varies among sites and years, and the relative timing of broods may affect their food availability [59]. In the main text, we present the results using the former date variable; see the Supplementary Material for results with the latter date variable (Table S2). Using diagnostic plots, we found that the trend between brood sex ratios and laying date was linear, thus any difference between first and second broods are adequately captured by date as a linear covariate. Nevertheless, we repeated our analyses using brood order (first or second per season) instead of date, and our results remained qualitatively unchanged (not shown).

All analyses were conducted using R version 3.4.2 [50]. To test whether the primary and fledgling sex ratios differed between study sites, we built generalized linear mixedeffects models with binomial error distribution and 'logit' link function (function glmmPQL in package MASS; [53]). The full models contained study site, year, laying date (either absolute date or the mean-centred laying date), tarsus length of the father and tarsus length of the mother as fixed effects and brood ID nested in pair ID as random factors. We also tested the interaction between study site and parents' tarsus length to study whether parental quality has different effects on offspring sex ratio in different populations. Because this interaction was nonsignificant in all models $(p>0.08)$, we present all model results without the interaction to facilitate easier interpretation of the main effects. Note that we did not include other parental body size variables (i.e. wing length, body mass) as predictors of brood sex ratio, because these traits can change considerably throughout the year and in several cases parents' size data were collected outside of their breeding period (see Field methods above). To increase our sample size, we repeated these analyses after excluding parents' tarsus length from the models, because we had data on both parents' tarsus length only in a subset of broods (see Supplementary Table S3 for sample sizes). Henceforward we refer to these analyses as 'reduced models'. Furthermore, to assess if our results were affected by imbalanced sample sizes due to the different frequency of second annual broods at the four sites, we repeated our sex ratio analyses after excluding the second broods.

To statistically compare the sex ratios between the two habitat types (urban sites vs. forest sites) we calculated linear contrasts from the full and reduced models. These linear contrasts were pre-planned comparisons between the two urban sites vs. the two forest sites (see also Pipoly et al. [48] and Vincze et al. [68] for the same approach to compare habitat types by pre-planned linear contrasts and for additional details of the method). Each linear contrast was back-transformed from the log-scale to provide the odds ratio (OR, i.e. the proportional difference of the odds of an offspring being male between urban and forest broods) with $95 \%$ confidence interval (CI). For the linear contrast analyses, we used the 'emmeans' function (emmeans package in R; [39]).

To investigate sexual size dimorphism in fledglings (measured at ringing, 14-16 days post-hatching), we used linear mixed-effects models (function lmer in package lme4; [9]). We built three separate models in which the response variables were the wing length, tarsus length or body mass of individual fledglings, respectively. In these three models, the fixed effects were study site, year, laying date (absolute date only) and sex of the fledgling, while brood ID nested in pair ID and crossed with measurer ID were included as random factors. To test if body size differences between male and female fledglings were different at the four study sites, we added the two-way interaction between sex and study site into these models. Any random variation among broods (including any difference in age) was taken into account by including brood ID as a random factor. We did not include fledgling age at ringing into the model because it varied in a very narrow range (14-16 days); note that Seress et al. [59] found no significant effect of fledgling age (within the same age range) on body mass in the same populations between 2013 and 2016.

To test for sex-dependent offspring survival, we analysed the effect of offspring sex on the probability of mortality to fledging. We used a generalized linear mixed-effects model 
Table 1 Primary and fledgling sex ratio of great tits in relation to study site, year, and laying date (absolute date, first and second annual broods pooled)

\begin{tabular}{|c|c|c|c|}
\hline & $\chi^{2}$ & $d f$ & $P$ \\
\hline \multicolumn{4}{|c|}{ Primary sex ratio } \\
\hline Sites & 2.040 & 3 & 0.564 \\
\hline Years & 0.036 & 2 & 0.982 \\
\hline Laying date & 1.655 & 1 & 0.198 \\
\hline \multicolumn{4}{|c|}{ Fledgling sex ratio } \\
\hline Sites & 1.707 & 3 & 0.635 \\
\hline Years & 0.430 & 2 & 0.807 \\
\hline Laying date & 2.563 & 1 & 0.109 \\
\hline
\end{tabular}

Effects are presented as analysis of deviance tables with type- 2 sums of squares for the reduced generalized mixed-effects models; $n=79$ and 126 for primary and fledgling sex ratios, respectively

with binomial error distribution and "logit" link function glmmPQL in package MASS [53]. The response variable was the status of offspring as alive (survived to day 14-16) or dead (unhatched eggs and dead chicks), the fixed effect was the sex of the offspring, and the model also included brood ID nested within-pair ID as random factors. Because offspring mortality was very rare, especially in forest sites (see Results), we did not test whether the sex difference in mortality differed between habitats.

All of the tested variables showed acceptable level of multicollinearity, as the variance inflation factor (VIF) varied from 1.04 to $1.22 \mathrm{in}$ all of the models. Based on residual plots and estimates of the dispersion parameter, all data conformed to the requirements of the applied statistical models.

\section{Results}

In our sample, primary sex ratio was overall 0.49 (95\% CI: $0.46-0.53)$, whereas fledgling sex ratio was 0.52 (95\% CI: 0.49-0.55) (for sample sizes see Table S2). For both primary and fledgling sex ratio, none of the tested predictors had significant effects either in the full model (see model estimates in Table S2 and S4) or in the reduced model (Table 1). Primary sex ratio was statistically close to parity at every study site (estimated mean $\pm \mathrm{SE}$, Veszprém city: $0.55 \pm 0.25$; Balatonfüred city: 0.46 \pm 0.39 ; Vilma-puszta forest: $0.46 \pm 0.26$; Szentgál forest: $0.48 \pm 0.25$; the $95 \%$ CI includes 0.5 for all sites, see Fig. 1) and did not differ significantly between urban and forest sites (Table 1). Fledgling sex ratio also did not deviate significantly from parity at any of the four sites (Veszprém city: $0.60 \pm 0.17$; Balatonfüred city: $0.51 \pm 0.48$; Vilma-puszta forest: $0.51 \pm 0.26$; Szentgál forest: $0.52 \pm 0.25$; the $95 \% \mathrm{CI}$ includes 0.5 for all sites, see Fig. 2), and there was no significant difference between

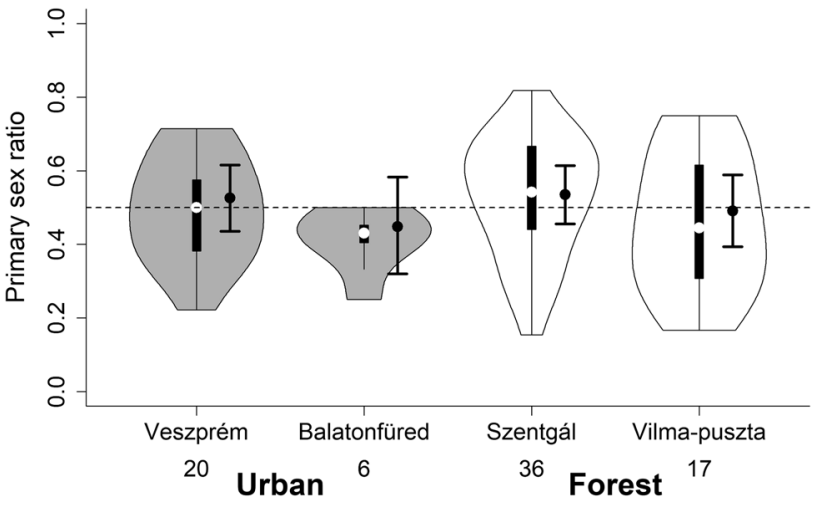

Fig. 1 Distribution of primary sex ratio (proportion of males) in broods at urban and forest study sites (first and second annual broods pooled). Each violin plot shows the median (indicated by the small, open circle), the first through the third interquartile range (the thick, solid vertical band), and minimum-maximum range (whiskers extending from the boxes) at each site. Curves around the box plots show the probability density of the data. Dots and whiskers next to the box plots show means and 95\% confidence intervals, respectively, both calculated from the model shown in Table 1. Numbers below the violin plots refer to the number of broods in each site

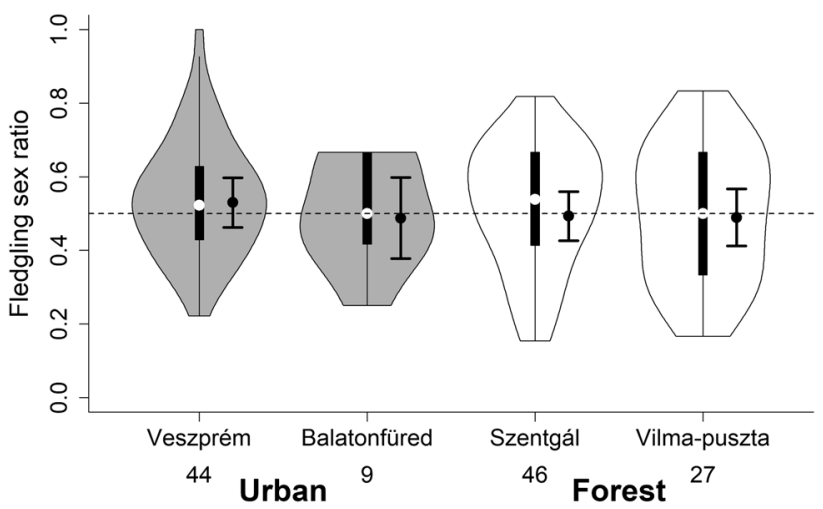

Fig. 2 Distribution of fledgling sex ratio (proportion of males) in broods at urban and forest study sites; see Fig. 1 for interpretation of plot elements

Table 2 Differences (pre-planned linear contrasts) in primary and fledgling sex ratios between urban and forest habitats, shown as odds ratios (OR; the proportional difference of the odds of an offspring being male at urban sites compared to forests)

\begin{tabular}{llrrl}
\hline & OR $(95 \%$ CI $)$ & $d f$ & \multicolumn{1}{l}{$t$} & $P$ \\
\hline Primary sex ratio & & & & \\
Full model & $0.87(0.71 ; 1.06)$ & 53 & -0.697 & 0.489 \\
Reduced model & $0.90(0.75 ; 1.09)$ & 72 & -0.549 & 0.584 \\
Fledgling sex ratio & & & & \\
Full model & $1.04(0.88 ; 1.23)$ & 96 & 0.236 & 0.814 \\
Reduced model & $1.07(0.92 ; 1.25)$ & 104 & 0.473 & 0.637 \\
\hline
\end{tabular}


urban and forest habitats (Table 2). These results were qualitatively identical when we eliminated the second annual broods from the models (see model estimates in Table S5 and Table S6).

Male fledglings had longer wings and tarsi and were heavier than female fledglings (Fig. 3, Table 3). These size differences between sexes were independent of the study site (interactions between the sex of the nestlings and study site were nonsignificant, Table 3). None of the body size parameters varied significantly with laying date or among years (Table S7).

In our sample, ten males and four females from ten broods died in the egg, and seven male and six female nestlings from nine broods died before ringing. The highest number of

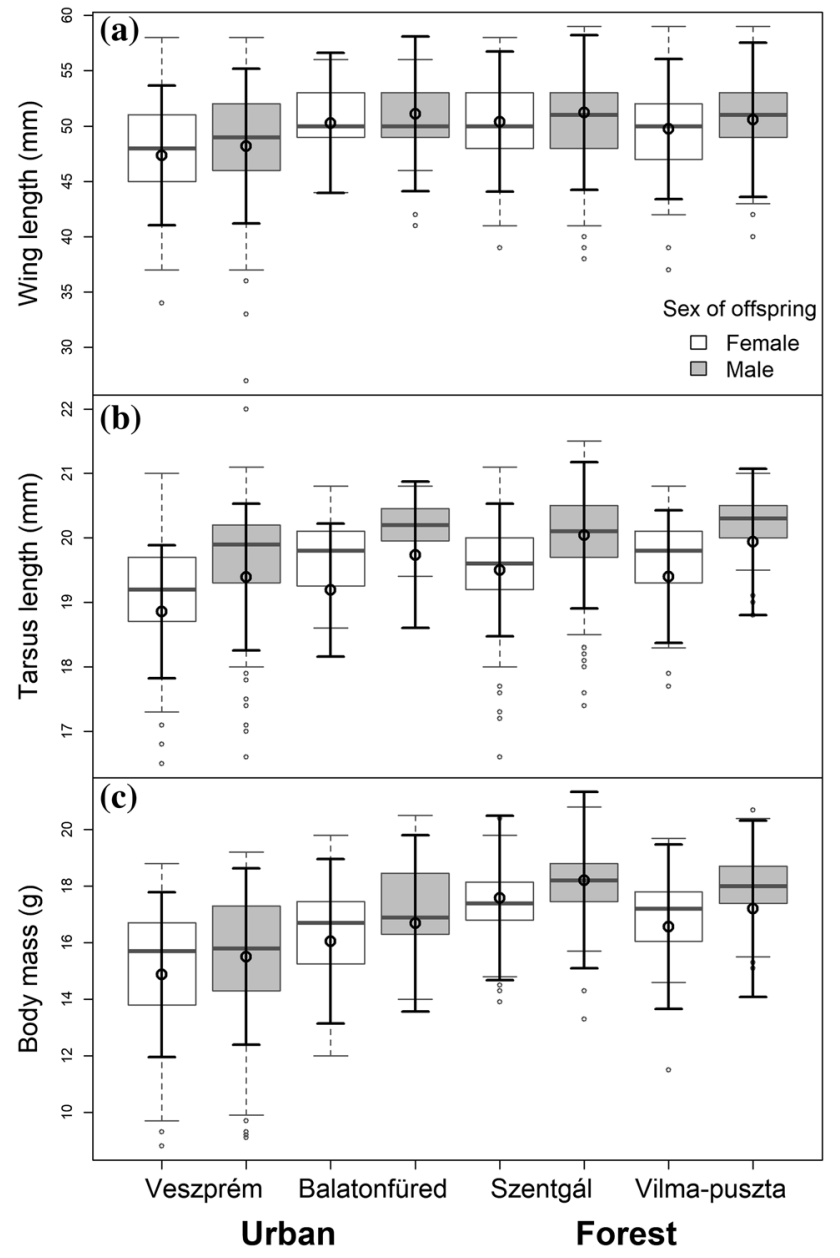

Fig. 3 Body size (a: tarsus length, $\mathbf{b}$ : wing length, and $\mathbf{c}$ : body mass) of male and female fledglings at the study sites. Box plots show the median, lower and upper quartiles, and the whiskers represent data within the $1.5 \times$ interquartile range. The open circles represent the outliers (data outside $1.5 \times$ the interquartile range above the upper quartile and below the lower quartile). The error bars show the mean with $95 \%$ CI estimated from the linear mixed models in Table 3. Details on parameter estimates for sex and site effects are provided in Table S6
Table 3 Results of the analyses of body size parameters of nestlings in relation to their sex, study site, years and laying date

\begin{tabular}{lclrr}
\hline & Mean squares & $d f$ & \multicolumn{1}{l}{$F$} \\
\hline Wing length & & & & \\
Sex & 35.649 & 1.1032 & 4.023 & 0.045 \\
Site & 39.238 & 3.98 & 4.427 & 0.006 \\
Years & 4.719 & 2.118 & 0.5324 & 0.588 \\
Laying date & 0.468 & 1.77 & 0.053 & 0.819 \\
Sex $\times$ site & 12.006 & 3.1035 & 1.355 & 0.255 \\
Tarsus length & & & & \\
Sex & 34.540 & 1.1035 & 148.430 & $<0.001$ \\
Site & 2.105 & 3.115 & 9.046 & $<0.001$ \\
Years & 0.244 & 2.129 & 1.049 & 0.353 \\
Laying date & 0.008 & 1.104 & 0.034 & 0.854 \\
Sex $\times$ site & 0.230 & 3.1038 & 0.990 & 0.397 \\
Body mass & & & & \\
Sex & 59.196 & 1.1024 & 66.219 & $<0.001$ \\
Site & 16.296 & 3.101 & 18.229 & $<0.001$ \\
Years & 0.891 & 2.122 & 0.996 & 0.372 \\
Laying date & 0.005 & 1.101 & 0.005 & 0.943 \\
Sex $\times$ site & 0.801 & 3.1025 & 0.896 & 0.443 \\
\hline
\end{tabular}

Effects are presented as analysis of deviance tables with type-2 sums of squares for the reduced generalized mixed-effects models. Nestlings of first $(n=952)$ and second annual broods $(n=200)$ were pooled in the analyses

dead offspring was found in Veszprém $(n=17)$, whereas at the other sites mortality was very low (Balatonfüred: $n=5$, Szentgál: $n=3$, Vilma-puszta: $n=2$ ). The sex ratio of dead offspring was 0.63 ( 0.59 in cities and 0.80 in forests); the proportional difference of the odds of mortality did not differ significantly between males and females $(\mathrm{OR}=1.50,95 \%$ $\mathrm{CI}=0.91-2.47, p=0.411$ ).

\section{Discussion}

Contrary to our prediction that great tit parents may overproduce daughters in food-limited urban habitats, we found that neither the primary nor the fledgling sex ratios differed significantly between urban and forest study sites. We consider these results robust, because we collected data over three breeding seasons at four study sites (two urban, two forest), and excluding the second annual broods did not change our results qualitatively (Tables S5 and S6). Our results differ from the findings of two other studies comparing great tits' offspring sex ratios between habitats of different quality. In one of these earlier studies, where the sexing of nestlings was based on visual cues [24], more male offspring were found in urban compared to suburban or woodland habitat before fledging. In the other study, Bouvier et al. [15] found more male nestlings in organic orchards with less pesticide 
use (that likely represent better habitat quality) than in orchards cultivated by using large amounts of pesticides. The reason for the varying results among these studies is unclear. Notably, the aforementioned studies showed information only about fledgling sex ratio, so to our knowledge, our study is the first that compares primary sex ratio between urban and forest habitats in great tits.

With the available information, we can only speculate why we did not find sex ratio adjustment in urban habitats. First, it is possible that in our study populations male or female offspring did not differ in the associated costs of producing and raising them until independence. However, 14-16 days old male fledglings were significantly heavier (by $3.6 \%$ ) and had slightly longer tarsi (by $2.5 \%$ ) and wings (by $2 \%$ ) compared to their female siblings, regardless of habitat type. These results suggest that male nestlings require more parental provisioning during their development than females, although we do not know the extent (and hence the associated additional costs) of such extra provisioning. Apparently, parents were able to meet this requirement in both habitats, because the size difference between male and female fledglings was similar in all study sites, and we did not find evidence for sex-related mortality (although the power of our mortality analyses was low due to the small sample size for dead offspring). This seems to contradict earlier studies in other great tit populations, which reported either male-biased sex ratio in unhatched eggs (Cichon et al. [21] or higher mortality in females before fledging (e.g. Smith et al. [62] and Lessells et al. [40]), and in some cases, the growth of females was more severely affected by poor environmental condition in tit species [46, 47]. To better understand these conflicting results, we need to have more data on the sex-specific mortality rates before and after hatching from our study populations, and also on the environmental factors and parental quality variables that can influence embryo and nestling survival. For example, it is possible that the increased resource requirement of male offspring induces male-biased mortality only under unusually poor environmental conditions, such as harsh weather, high prevalence of parasites or disease, or extremely low food supply [66].

Given that the larger size of male fledglings suggests higher parental cost, a potential explanation for the lack of sex ratio adjustment is that there may be some unknown cost to producing female offspring that cancels out the differences in the pay-off between the sexes. For example, it is possible that survival chances are lower after fledging for females than for males. The most dangerous period in the life of juvenile great tits is the dispersion after fledging: Naef-Daenzer et al. [45] found that $47 \%$ of the juveniles died during the first 20 days after fledging. Adalsteinsson et al. [1] found that in urban habitat crossing the roads and collisions with building could increase the mortality in young birds, but they had not enough data to analyse separately the mortality of sexes. Female great tits disperse farther than males [4], which may mean higher risk of mortality for juvenile females, especially in urban habitats where potential breeding and feeding sites are more fragmented by built-up areas and roads with heavy traffic. Furthermore, survival during autumn and winter may also differ between the sexes in a habitat-dependent manner. In urban areas, seeds and other food in artificial feeders can increase the chance of survival [43], but competition at these feeders may be stronger than at natural feeding sites such as tree canopies. At feeders, social rank might limit access to food, because subordinate individuals may be attacked by dominant ones and therefore get less food. In great tits, males are more often dominant than females, especially in juveniles (e.g. Barluenga et al. [7] and Dingemanse and de Goede [25]). These sex differences in great tit life history may generate female-biased juvenile mortality, especially in urban habitats. However, the only published study that compared the sex-specific survival of great tits between urban and rural habitats found higher adult female than male survival in both habitats, and yearling females outnumbered yearling males in the next year breeding season [30].

We found remarkably high variance of sex ratios among individual broods in both habitat types (primary sex ratio, range in urban habitat: $0.22-0.71$, in forest habitat: $0.15-0.82$; fledgling sex ratio, urban: $0.22-1.00$, forest: $0.15-0.84)$. This variance in our data was not explained by laying date and the parents' tarsus length, representing proxies for seasonal environmental changes and for parental quality, respectively. One interpretation of this high variance is that parents vary in their investment into their offspring's sex, but their allocation is determined by factors which we did not investigate. For example, Lessells et al. [40] reported that the proportion of male offspring increased with hatching asynchrony in great tits. Furthermore, Pipoly et al. [48] found in the same populations and breeding seasons as in the present study that the number of extra-pair offspring was higher in urban habitats than in forests, which might influence sex ratio adjustment. The other possible interpretation of our findings is that the observed variance in brood sex ratios is largely random, with no facultative sex ratio adjustment going on. For example, in urban areas, where the environmental changes may be rapid and unpredictable, sex ratio manipulation might not be a profitable strategy, as it may be difficult for parents to predict the conditions their offspring will find themselves in. So far, there have been very few studies on great tit primary sex ratios, and their results provided little if any evidence that the observed variation among nests is adaptive [33, 40]. 


\section{Conclusion for future biology}

Taking our results together with the small number of previous findings, the role of facultative sex ratio adjustment in birds' adaptation to urban life is not yet clear. Further studies are needed to better understand the prevalence of sex ratio adjustment and drivers of offspring sex ratio in an urbanization context. For example, we should study different environmental predictors that may differ between anthropogenic and natural habitats and may lead to differences in the costs and benefits of male and female offspring, influencing sex ratio adjustment. Research is needed also on the sex-dependent effects of urbanization on life history traits and thus the fitness pay-offs of producing sons and daughters along the urbanization gradient, including sex-related post-fledging survival and future breeding success of male and female offspring in different habitat types. Furthermore, urbanization may interact with other anthropogenic influences such as climate change, potentially resulting in complex effects on sex ratios if males and females differ in their sensitivities to these various perils.

Acknowledgements Open access funding provided by University of Pannonia. The authors hereby thank all former and current members of the MTA-PE Evolutionary Ecology Research Group who contributed to the fieldwork producing the data for this study. We are grateful to the members of Conservation Genetics Research Group of the University of Veterinary Medicine who helped in the laboratory work.

Author's contribution IP, EV, VB, GS and AL collected the data in the field. NÁ, IP and KSZ conducted the molecular work. NÁ, IP, EV, VB, GS and AL participated in conceptualization, design and data analysis and manuscript writing.

Funding This work was supported by the Hungarian Scientific Research Fund (NKFIH K84132, K112838). NÁ was supported by the Hungarian Ministry of Human Capacities (National Talent Program, grant number NTP-NFTÖ-18-B-0376), GS was supported by an NKFIH postdoctoral Grant (PD 120998).

\section{Compliance with ethical standards}

Conflict of interest The authors declare no competing interests.

Ethical approval All applicable international, National and/or Institutional Guidelines for the care and use of animals were followed. Research was permitted by the Middle Transdanubian Inspectorate for Environmental Protection, Natural Protection and Water Management (Permission Number: 31559/2011). All procedures were in accordance with the guidelines for animal care outlined by ASAB/ABS and Hungarian laws.

Open Access This article is licensed under a Creative Commons Attribution 4.0 International License, which permits use, sharing, adaptation, distribution and reproduction in any medium or format, as long as you give appropriate credit to the original author(s) and the source, provide a link to the Creative Commons licence, and indicate if changes were made. The images or other third party material in this article are included in the article's Creative Commons licence, unless indicated otherwise in a credit line to the material. If material is not included in the article's Creative Commons licence and your intended use is not permitted by statutory regulation or exceeds the permitted use, you will need to obtain permission directly from the copyright holder. To view a copy of this licence, visit http://creativecommons.org/licenses/by/4.0/.

\section{References}

1. Adalsteinsson SA, Buler JJ, Bowman JL, D'Amico V, Ladin ZS, Shriver WG (2018) Post-independence mortality of juveniles is driven by anthropogenic hazards for two passerines in an urban landscape. J Avian Biol 49:e01555. https://doi.org/10.1111/ jav.01555

2. Anderson DJ, Reeve J, Gomez JEM, Weathers WW, Hutson S, Cunningham HV, Bird DM (1993) Sexual size dimorphism and food requirements of nestling birds. Can J Zool 71:2541-2545

3. Anderson DJ, Reeve J, Bird D (1997) Sexually dimorphic eggs, nestling growth and sibling competition in American kestrels Falco sparverius. Funct Ecol 11:331-335

4. Andreu J, Barba E (2006) Breeding dispersal of great tits Parus major in a homogeneous habitat: effects of sex, age, and mating status. Ardea 94:45-58

5. Badyaev A, Whittingham L, Hill G (2001) The evolution of sexual size dimorphism in the house finch. III. Developmental basis. Evolution 55:176-189

6. Bailly J, Scheifler R, Berthe S, Clément-Demange V-A, Leblond M, Pasteur B, Faivre B (2015) From eggs to fledging: negative impact of urban habitat on reproduction in two tit species. J Ornithol 157:377-392. https://doi.org/10.1007/s1033 6-015-1293-3

7. Barluenga M, Barbosa A, Moreno E (2000) Social relationships due to sex, age and morphology in great tits Parus major wintering in a mountainous habitat of Central Spain. Ardeola 47:19-27

8. Barrett E, Richardson D (2011) Sex differences in telomeres and lifespan. Aging Cell 10:913-921

9. Bates D, Maechler M, Bolker B, Walker S (2014) Fitting linear mixed-effects models using lme4. J Stat Soft 1406:5823

10. Bell S, Owens I, Lord A (2014) Quality of breeding territory mediates the influence of paternal quality on sex ratio bias in a free-living bird population. Behav Ecol 25:352-358

11. Biard C, Brischoux F, Meillère A, Meillère A, Michaud B, Nivière M, Ruault S, Vaugoyeau M, Angelier F (2017) Growing in cities: an urban penalty for wild birds? A study of phenotypic differences between urban and rural Great Tit chicks (Parus major). Front Ecol Evol 5:79. https://doi.org/10.3389/fevo.2017.00079

12. Bize P, Roulin A, Tella JL, Richner H (2005) Female-biased mortality in experimentally parasitized Alpine Swift Apus melba nestlings. Funct Ecol 19:405-413

13. Bonderud E, Otter K, Murray BW, Marini KLD, Burg TM, Reudink MW (2017) Effects of parental condition and nesting habitat on sex allocation in the mountain chickadee. Behaviour 154:1101-1121

14. Booksmythe I, Mautz B, Davis J, Nakagawa S, Jennions MD (2017) Facultative adjustment of the offspring sex ratio and male attractiveness: a systematic review and meta-analysis. Biol Rev 92:108-134. https://doi.org/10.1111/brv.12220

15. Bouvier J, Boivin T, Charmantier A, Lambrechts M, Lavigne C (2016) More daughters in a less favourable world: breeding in intensively-managed orchards affects tertiary sex-ratio in the Great Tit. Basic Appl Ecol 17:638-647

16. Burfield IJ, van Bommel F (2004) Birds in Europe: population estimates, trends and conservation status (birdlife conservation). BirdLife International 
17. Burley N (1981) Sex ratio manipulation and selection for attractiveness. Science 211(211):721-722. https://doi.org/10.1126/scien ce.211.4483.721

18. Burley N (1986) Sex-ratio manipulation in color-banded populations of Zebra Finches. Evolution 40:1191-1206. https://doi. org/10.2307/2408947

19. Chamberlain D, Cannon AR, Toms MP, Leech DI, Hatchwell BJ, Gaston KJ (2009) Avian productivity in urban landscapes: a review and meta-analysis. Ibis 151:1-18. https://doi.org/10.1111/ j.1474-919X.2008.00899.x

20. Charmantier A, Demeyrier V, Lambrechts M, Perret S, Grégoire A (2017) Urbanization is associated with divergence in pace-oflife in great tits. Front Ecol Evol 5:53. https://doi.org/10.3389/ fevo.2017.00053

21. Cichon M, Sendecka J, Gustafsson L (2005) Male-biased sex ratio among unhatched eggs in Great Tit Parus major, Blue Tit P. caeruleus and Collard Flycatcher Ficedula albicollis. J Avian Biol 36:386-390

22. Cordero PJ, Griffith SC, Aparicio JM, Parkin DT (2000) Sexual dimorphism in house sparrow eggs. Behav Ecol Sociobiol 48:353-357. https://doi.org/10.1007/s002650000252

23. Cordero PJ, Vinuela J, Aparicio JM, Veiga JP (2001) Seasonal variation in sex ratio and sexual egg dimorphism favouring daughters in first clutches of the spotless starling. J Evol Biol 14:829-834

24. Dhondt AA (1970) The sex ratio of nestling great tits. Bird Study 17:282-286

25. Dingemanse N, de Goede P (2004) The relation between dominance and exploratory behavior is context-dependent in wild great tits. Behav Ecol 15(6):1023-1030

26. Griffiths R, Double MC, Orr K, Dawson RJG (1998) A DNA test to sex most birds. Mol Ecol 7:1071-1075. https://doi.org/10.1046/ j.1365-294x.1998.00389.x

27. Hinsley S, Hill R, Bellamy P, Harrison NM, Speakman JR, Wilson AK, Ferns PN (2008) Effects of structural and functional habitat gaps on breeding woodland birds: working harder for less. Lanscape Ecol 23:615-626

28. Hochachka WM, Smith J (1991) Determinants and consequences of nestling condition in song sparrows. J Anim Ecol 60:995-1008

29. Hõrak P (1993) Low fledging success of urban great tits. Ornis Fenn 70:168-172

30. Hõrak P, Lebreton J (1998) Survival of adult great tits Parus major in relation to sex and habitat; a comparison of urban and rural populations. Ibis 140(2):205-209

31. Howe H (1977) Sex-ratio adjustment in the common grackle. Science 198:744-746

32. Julliard R (2000) Sex-specific dispersal in spatially varying environ- ments leads to habitat-dependent evolutionarily stable offspring sex ratios. Behav Ecol 11:421-428

33. Kabasakal B, Albayrak T (2012) Offspring sex ratios and breeding success of a population of the Great Tit, Parus major. Zool Mid East 57:27-34. https://doi.org/10.1080/09397140.2012.10648960

34. Kalmbach E, Nager R, Griffiths R, Furness RW (2001) Increased reproductive effort results in male-biased offspring sex ratio: an experimental study in a species with reversed sexual size dimorphism. Proc R Soc B Biol Sci 268:2175-2179

35. Komdeur J (1996) Facultative sex ratio bias in the offspring of Seychelles warblers. Proc R Soc B Biol Sci 263:661-666

36. Komdeur J, Pen I (2002) Adaptive sex allocation in birds: the complexities of linking theory and practice. Philos Trans R Soc B Biol Sci 357:373-380. https://doi.org/10.1098/rstb.2001.0927

37. Korpimäki E, May CA, Parkin DT, Wetton JH, Wiehen J (2000) Environmental- and parental condition-related variation in sex ratio of Kestrel broods. J Avian Biol 31:128-134
38. Kölliker M, Heeb P, Werner I, Mateman AC, Lessells CM, Richner $H$ (1999) Offspring sex ratio is related to male body size in the Great Tit (Parus major). Behav Ecol 10:68-72

39. Lenth R, Lenth M (2018) Package 'Ismeans'. Am Stat 34:216-221

40. Lessells CM, Mateman AC, Visser J (1996) Great Tit hatchling sex ratios. J Avian Biol 27:135-142. https://doi.org/10.2307/3677142

41. Liker A, Székely T (2005) Mortality costs of sexual selection and parental care in natural populations of birds. Evolution 59:890 897. https://doi.org/10.1111/j.0014-3820.2005.tb01762.x

42. Martins T (2004) Sex-specific growth rates in zebra finch nestlings: a possible mechanism for sex ratio adjustment. Behav Ecol $15: 174-180$

43. Marzluff J (2017) A decadal review of urban ornithology and a prospectus for the future. Ibis 159:1-13

44. Massemin S, Korpimäki E, Wiehn J (2000) Reversed sexual size dimorphism in raptors: evaluation of the hypotheses in kestrels breeding in a temporally changing environment. Oecologia 124:26-32

45. Naef-Daenzer B, Nuber M, Widmer F (2001) Differential postfledging survival of Great and Coal Tits in relation to their condition and fledging date. J Anim Ecol 70:730-738

46. Nomi D, Yuta T, Koizumi I (2018) Seasonal change in sexual differences in nestling size and survival: a framework to evaluate sex-dependent environmental sensitivity in the wild. Avian Res 9:10. https://doi.org/10.1186/s40657-018-0102-0

47. Oddie K (2000) Size matters: competition between male and female Great Tit offspring. J Anim Ecol 69:903-912

48. Pipoly I, Szabó K, Bókony V, Preiszner B, Seress G, Vincze E, Liker A (2019) Higher frequency of extra-pair offspring in urban than forest broods of great tits (Parus major). Fron Ecol Evol 7:229. https://doi.org/10.3389/fevo.2019.00229

49. Pryke S, Rollins L (2012) Mothers adjust offspring sex to match the quality of the rearing environment. Proc R Soc B Biol Sci 279:4051-4057

50. R Development Core Team (2017) A language and environment for statistical computing. R Foundation for Statistical Computing, Vienna, Austria

51. Råberg L, Stjernman M, Nilsson JÅ (2005) Sex and environmental sensitivity in blue tit nestlings. Oecologia 145:496-503. https:// doi.org/10.1007/s00442-005-0133-1

52. Rejt L, Gryczynska-Siemaiatkowska A, Rutkowski R, Malewska A (2005) Does egg sex ratio in urban kestrels (Falco tinnunculus) differ from parity? Pol J Ecol 53:545-552

53. Ripley BD, Venables WN, Bates DM, Hornik K, Gebhardt A, Firth D, Ripley MB (2013) Package "MASS." CRAN Repos

54. Rosivall B, Szöllősi E, Hasselquist D, Török J (2010) Males are sensitive: sex-dependent effect of rearing conditions on nestling growth. Behav Ecol Sociobiol 64:1555-1562. https://doi. org/10.1007/s00265-010-0969-1

55. Rosivall B, Török J, Hasselquist D, Bensch S (2004) Brood sex ratio adjustment in collared flycatchers (Ficedula albicollis): results differ between populations. Behav Ecol Sociobiol 56:346-351

56. Sepp T, McGraw KJ, Kaasik A, Giraudeau M (2018) A review of urban impacts on avian life-history evolution: does city living lead to slower pace of life? Glob Chang Biol 24:1452-1469. https ://doi.org/10.1111/gcb.13969

57. Seress G, Liker A (2015) Habitat urbanization and its effects on birds. Acta Zool Acad Sci Hungaricae 61:373-408

58. Seress G, Vincze E, Pipoly I, Hammer T, Papp S, Preiszner B, Bókony V, Liker A (2017) Effects of capture and video-recording on the behavior and breeding success of great tits in urban and forest habitats. J Field Ornithol 88:299-312

59. Seress G, Hammer T, Bókony V, Vincze E, Preiszner B, Pipoly I, Cs Sinkovics, Evans KL, Liker A (2018) Impact of urbanization 
on abundance and phenology of caterpillars and consequences for breeding in an insectivorous bird. Ecol Appl 28:1143-1156. https ://doi.org/10.1002/eap.1730

60. Seress G, Sándor K, Evans KL, Liker A (2020) Food availability limits avian reproduction in the city: an experimental study on great tits Parus major. J Anim Ecol. https://doi. org/10.1111/1365-2656.13211

61. Seutin G, White BN, Boag PT (1991) Preservation of avian blood and tissue samples for DNA analyses. Can J Zool 69:82-90

62. Smith H, Kallander H, Nilsson J-A (1989) The trade-off between offspring number and quality in the Great Tit Parus major. J Anim Ecol 58:383-401. https://doi.org/10.2307/4837

63. Stauss M, Segelbacher G, Tomiuk J, Bachmann L (2005) Sex ratio of Parus major and $P$. caeruleus broods depends on parental condition and habitat quality. Oikos 109:367-373

64. Svensson L (1992) Identification guide to European passerines. Stockholm. ISBN 9163011182

65. Szász E, Kiss D, Rosivall B (2012) Sex ratio adjustment in birds. Ornis Hung 20:26-36. https://doi.org/10.2478/orhu-2013-0002
66. Tschirren B, Fitze PS, Richner H (2003) Sexual dimorphism in susceptibility to parasites and cell-mediated immunity in great tit nestlings. J Anim Ecol 72:839-845. https://doi.org/10.104 6/j.1365-2656.2003.00755.x

67. Végvári Z, Katona G, Vági B, Freckleton RP, Gaillard JM, Székely T, Liker A (2018) Sex-biased breeding dispersal is predicted by social environment in birds. Ecol Evol 8:6483-6491. https://doi. org/10.1002/ece3.4095

68. Vincze E, Pipoly I, Seress G, Preiszner B, Papp S, Németh B, Liker A, Bókony V (2019) Great Tits take greater risk toward humans and sparrowhawks in urban habitats than in forests. Ethology 125:686-701. https://doi.org/10.1111/eth.12922

69. West SA, Herre E, Sheldon BC (2000) The benefits of allocating sex. Science 290:288-290. https://doi.org/10.1126/scien ce. 290.5490 .288

70. Yamaguchi N, Kawano KK, Eguchi K, Yahara T (2004) Facultative sex ratio adjustment in response to male tarsus length in the Varied Tit Parus varius. Ibis 146:108-113. https://doi. org/10.1111/j.1474-919X.2004.00220.x 